\title{
Accidental intracranial infusion of parenteral nutrition in a preterm neonate
}

\author{
Amir Ahmadian, MD, ${ }^{1}$ Jotham Manwaring, MD, ${ }^{1}$ Devon Truong, PA-C, ${ }^{2}$ Jeane McCarthy, MD, ${ }^{3}$ \\ Luis F. Rodriguez, MD, ${ }^{1,2}$ Carolyn M. Carey, MD, ${ }^{1,2}$ and Gerald F. Tuite, MD ${ }^{1,2}$ \\ ${ }^{1}$ Department of Neurosurgery and Brain Repair, University of South Florida Morsani School of Medicine, Tampa; and \\ ${ }^{2}$ Neuroscience Institute and ${ }^{3}$ Department of Neonatology, All Children's Hospital/Johns Hopkins Medicine, St. Petersburg, Florida
}

\begin{abstract}
Vascular access in the neonate can be challenging, especially in preterm infants. When other access is not available, superficial scalp veins can be safely used for vascular access. However, rare and potentially catastrophic complications can occur due to unique features of the neonatal skull and soft-tissue anatomy. The authors report a rare complication of vascular access in a preterm infant, which led to the direct infusion of parenteral nutrition into the intracranial space. The child had an excellent outcome after open drainage and irrigation of bilateral intracranial spaces and the spinal thecal sac. Relevant anatomy is illustrated, and an outcome-based literature review is presented on this rarely reported condition. Surgical and conservative management strategies are discussed, along with clinical and radiographic follow-up. Drainage and irrigation is advocated in patients with mass effect, viscous effusions, or declining neurological examination findings.
\end{abstract}

http://thejns.org/doi/abs/10.3171/2015.3.PEDS1334

KEY WORDS parenteral nutrition; preterm; neonate; subdural infusion; scalp venous access

$\mathrm{M}$ OST preterm infants need intravenous access for antibiotics, fluids, prostaglandin $\mathrm{E}$, parenteral nutrition $(\mathrm{PN})$, or other medications. Central venous catheters are often used for longer-term vascular access and administration of PN. Central venous catheter-related complications such as venous thrombosis, pulmonary embolism, retrograde flow, extravasation, and infections have been well described..$^{10,12,15}$ Administration of intravenous products through peripherally inserted central catheters or peripherally inserted intravenous catheters reduces the inherent risks associated with central venous catheters ${ }^{3,4}$ Finding an adequate peripheral vein for access in a neonate, other than the umbilical vein, can be quite difficult due to small vein caliber in the extremities. Scalp veins often offer easier access, being used in up to $50 \%$ of premature neonates in some series. ${ }^{7}$ Widely open fontanelles and sutures raise the possibility of inadvertent intra- cranial infusion. In this report, we present an exceedingly rare case of accidental intracranial infusion of PN and its neurosurgical management.

\section{Case Report}

Birth History and Clinical Course in the First 10 Days of Life

A female infant was delivered by cesarean section at 31 weeks' gestation, weighing 1040 g, after a pregnancy complicated by oligohydramnios and intrauterine growth restriction. Apgar scores were 8 at both 1 and 5 minutes. The 1st week of life was complicated by mild hyperbilirubinemia, mild respiratory distress syndrome, and methicillin-sensitive Staphylococcus aureus sepsis. Intravenous antibiotics and parenteral nutrition were started on Day 2 of life through the umbilical vein. Due to failed venous access on Day 10 of life, a peripheral scalp intravenous

ABBREVIATIONS ICP = intracranial pressure; $\mathrm{PN}=$ parenteral nutrition; $\mathrm{TPN}=$ total $\mathrm{PN}$. SUBMITTED January 24, 2013. ACCEPTED March 20, 2015.

INCLUDE WHEN CITING Published online July 17, 2015; DOI: 10.3171/2015.3.PEDS1334.

DISCLOSURE The authors report no conflict of interest concerning the materials or methods used in this study or the findings specified in this paper. 
catheter was placed in the supratrochlear vein parallel to the metopic suture at the anterior-most aspect of the anterior fontanelle.

\section{Diagnosis of Intracranial Infusion of Total Parenteral Nutrition}

The child's head circumference increased by $2 \mathrm{~cm}$ in the 2 days following commencement of $\mathrm{PN}$ infusion through the scalp intravenous catheter. The fontanelle was tense and bulging, accompanied by a widely split sagittal suture. A cranial ultrasound revealed new, large bilateral subdural effusions with mass effect. A small bolus of fluid was infused through the scalp intravenous catheter during cranial ultrasonography, which revealed turbulent flow directly within the subdural space, suggesting direct infusion into the intracranial compartment. The intravenous catheter was then immediately removed, allowing egress of a milky substance from the puncture site (Fig. 1A). The patient was then transferred to our center for neurosurgical evaluation.

On arrival, milky white fluid, consistent with parenteral nutrition/intralipids, continued to ooze from the previous scalp intravenous catheter site, accompanied by clinical signs of high intracranial pressure (ICP) (Fig. 1A). During the primary evaluation the neonate was noted to be tachycardic, tachypnic, and irritable with abnormal brief extensor posturing movements. CT scanning revealed pneumocephalus in the region of the scalp intravenous catheter and a dilated subdural space (Fig. 2A). A lumbar puncture also revealed viscous, milky fluid that was difficult to drain through a spinal needle. Subsequent surgical evacuation was performed due to evidence of raised ICP, poor neurological status, and vital sign instability.

\section{Operative Management and Hospital Course}

The patient was taken emergently to the operating room for bilateral subdural and intrathecal drainage and irrigation. The dura was opened bilaterally at the coronal sutures, exposing pressurized subdural compartments filled with copious amounts of viscous milky fluid (Video 1; Fig. 1C).

VIDEO 1. Bilateral craniotomies. Bilateral craniotomies performed at the coronal suture show efflux of pressurized, viscous "milky" fluid from the subdural/subarachnoid space consistent with parental nutrition. Copyright Gerald Tuite. Published with permission. Click here to view with Media Player. Click here to view with Quicktime.

The subdural space was irrigated until clear, and bilateral subdural drains were left. Based on the preoperative lumbar puncture findings, an intrathecal lumbar drain was placed through a single-level lower lumbar laminectomy after the intrathecal space was copiously irrigated.

The subdural compartment was irrigated daily with preservative-free saline through the subdural drains, and the triglyceride level was followed serially. After 3 days of drainage, the triglyceride level improved from 1698 $\mathrm{mmol} / \mathrm{L}$ to $15 \mathrm{mmol} / \mathrm{L}$, allowing for drain removal. Due to the infant's recent methicillin-sensitive $S$. aureus sepsis and risk for fungal infection from the subdural PN infusion, she was treated with oxacillin and fluconazole for 1 week after surgery. Postoperative MRI showed a small superficial cystic area within the right frontal lobe deep to the intravenous catheter site, as well as a decompressed

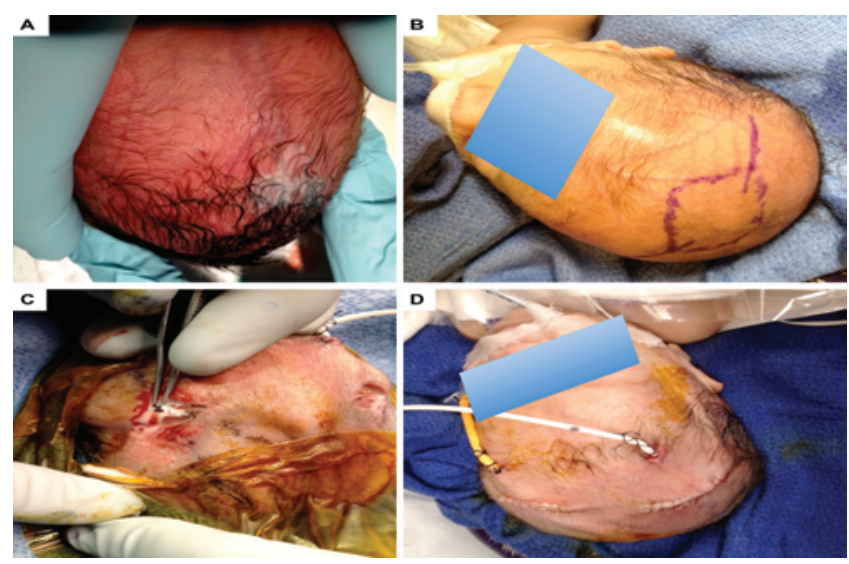

FIG. 1. Intraoperative photographs. A: Milky discharge directly from the puncture site. B: Enlarged head with outlined coronal suture and anterior fontanelle. C: Intraoperative photograph with craniotomies at the coronal suture and evidence of milky fluid within the cranial cavity. D: Postoperative photograph with bilateral subdural drains.

subdural compartment (Fig. 2B and C). The parenchymal abnormality was noted on the initial diagnostic cranial ultrasound.

The infant had an uneventful recovery after surgery, with neurological examination findings consistent with her prematurity. No hydrocephalus, seizures, infection, or raised ICP developed within the 1st year of follow-up. No permanent CSF diversion was required. She made neurological gains typical for a premature child, with mild motor delay. Her head circumference paralleled the 25th percentile, similar to her weight and length. MRI performed at 1 year showed minimal focal cortical gliosis (Fig. 2C).

\section{Discussion}

\section{Indications and Dangers of Scalp Vein Access}

Prolonged venous access is necessary in the sick, premature neonate. The most common indications are the need for antibiotic therapy, PN, intravenous fluids, vitamin E infusion, or administration of other medications. Proximal extremity veins should be preserved for peripherally inserted central catheter or central line placement, and distal sites can be difficult to manage due to neighboring joints and extremity mobility. Umbilical access may be available up to several days after parturition, but this is not a good option for long-term access. For these reasons, the scalp has often been the site of choice for long-term intravenous access in a premature infant.

The scalp of the neonate provides 4 reasonable options for venous access: the supratrochlear, anterior facial, superficial temporal, and posterior auricular veins (Fig. 3). The absence of bone at the sutures and fontanelles creates unique anatomy in the neonate. Identifying a "danger zone" related to the vein of interest is crucial for complication avoidance (Fig. 3). A danger zone includes a superficial scalp vein, its associated underlying suture and fontanelle, and the underlying dural venous sinus. Insertion techniques for venous access should be directed away from the suture with blood return to confirm intravenous 

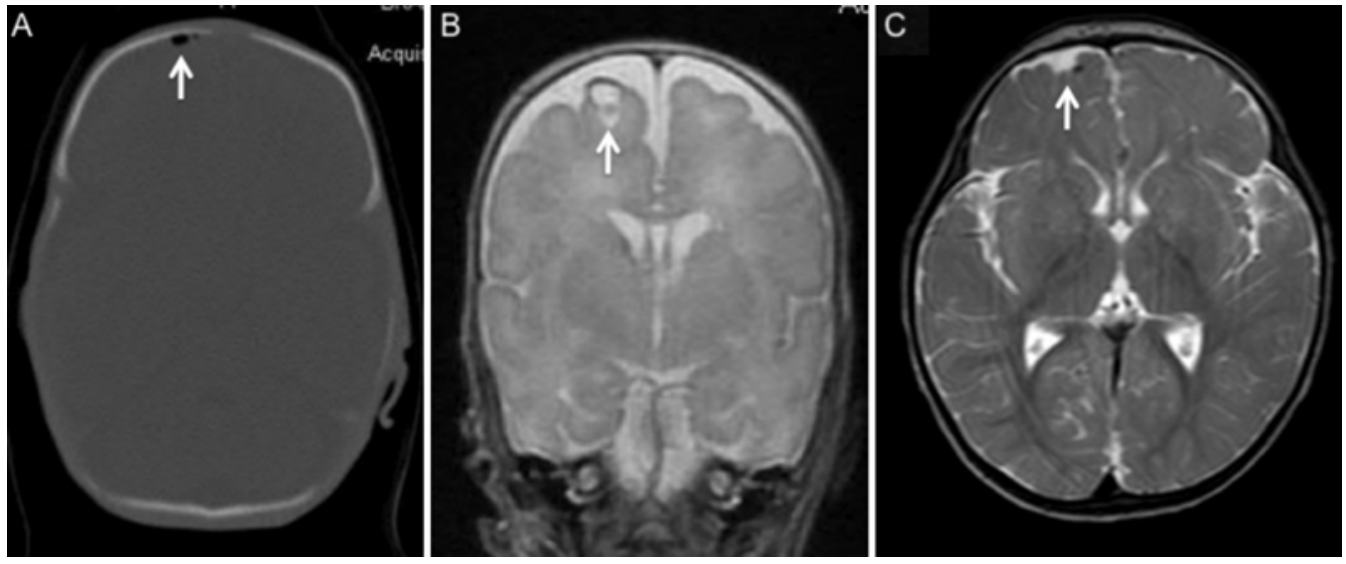

FIG. 2. CT and MRI radiographic evaluation. A: CT scan of the head (bone window) obtained at the time of initial evaluation, showing right frontal hypodensity consistent with pneumocephalus. B: Coronal T2-weighted MR image obtained during the initial hospitalization, showing right frontal intraparenchymal cystic area. C: Axial T2-weighted MR image obtained 1 year postoperatively with evidence of mild right frontal gliosis and focal atrophy.

placement. Ultrasound can be used to confirm catheter placement within the superficial vein as opposed to dural venous sinus..$^{5}$ We propose that one way to avoid intracranial placement may be to place a scalp intravenous catheter only over bone and not over a fontanelle or an open suture line. Despite these efforts, inadvertent intracranial infusion may be unavoidable in some circumstances.

\section{Possible Mechanisms for Intracranial Infusion}

Inadvertent intracranial infusion of intravenous fluids, blood products, and PN can be related to direct infusion of a misplaced catheter or due to retrograde flow through thrombosed, valveless scalp veins that communicate with the intracranial compartment. ${ }^{1,2,9,11-13}$ Tuthill et al. showed a transudative ultrafiltrate of total PN (TPN) in the subdural space rather than pure intralipid, ${ }^{14}$ supporting the notion of intracranial infusion even in the presence of a correctly placed subcutaneous venous catheter. In our case, pure unfiltered TPN and intralipids were found in the subdural space, suggesting direct infusion.

\section{Management Strategies and Literature Review}

Many complications have been associated with scalp intravenous access, including air embolism, retrograde flow, inadvertent subdural placement, and subdural infusion of packed red blood cells. ${ }^{2,6,8}$ Intracranial infusion of PN has been rarely reported, with variable consequences, including fungal infection, seizures, hydrocephalus, and death. ${ }^{1}$ Separating poor outcomes related to intracranial infusion of PN from other complications of prematurity is difficult because of limited detail available in previous case reports (Table 1).

Inadvertent PN subdural infusion has been managed with supportive care, subdural aspiration, or subdural drain placement in previously published cases. Initial reports of supportive care described over 30 years ago resulted in death in both patients, ${ }^{1,2}$ but a good outcome was described in a 2004 report of a patient treated with only supportive care. ${ }^{6}$ Similarly, subdural aspiration has result- ed in disparate results; 2 patients died and 2 others had a good outcome. ${ }^{10-12,14,16}$

Rare postmortem studies after intracranial PN infusion have provided conflicting results. One autopsy showed lipid-laden macrophages with gliosis, ${ }^{3}$ another showed marked pleocytosis, ${ }^{1}$ and a third case showed no inflammatory change. ${ }^{2}$ We cannot make any definite conclusions about the inflammatory response in our patient because a brain biopsy was not performed at the time of drainage.

We considered observation, aspiration, and drainage in the management of our patient. The initial lumbar puncture revealed viscous, milky fluid. The presence of PN in the spinal subdural space from a hemispheric convexity infusion indicated a global intracranial and spinal space involvement rather than a focal collection. The patient's increasing head circumference, deteriorating neurological examination findings, the viscosity of the fluid obtained on lumbar puncture, and associated poor outcomes previously reported in the literature prompted surgical intervention. We chose to perform an open procedure instead

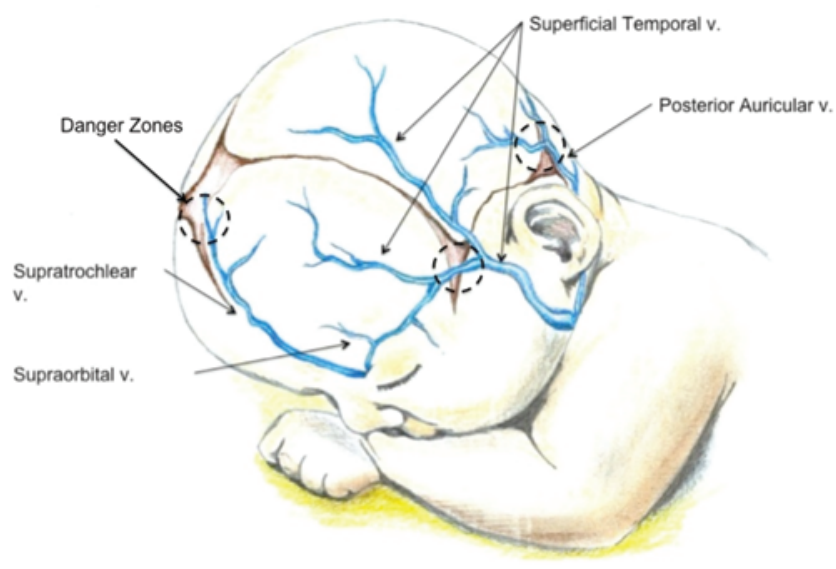

FIG. 3. Illustration of safe zones for venous access. v. = vein. Artist: Devon Truong. Published with permission from Jennifer Clare Truong. 
TABLE 1. Literature review of intracranial infusion and outcomes

\begin{tabular}{|c|c|c|c|c|c|}
\hline Authors \& Year & $\begin{array}{l}\text { Adjusted } \\
\text { Age/Sex }\end{array}$ & $\begin{array}{l}\text { Follow-Up } \\
\text { Interval }\end{array}$ & Outcome & Management & Notes \\
\hline Black et al., 1978 & 30 wks, F & 100 days & Death & $\begin{array}{l}\text { Stopped infusion, removed catheter, sup- } \\
\text { portive }\end{array}$ & $\begin{array}{l}\text { Died of severe PNA unresponsive to } \\
\text { treatment at } 100 \text { days of age }\end{array}$ \\
\hline Beaumont et al., 1982 & Term, M & 6 wks & Death & $\begin{array}{l}\text { Stopped infusion, removal of catheter, os- } \\
\text { motic diuretics, hyperventilation, steroids }\end{array}$ & $\begin{array}{l}\text { Omphalocele; infusion of PN \& ampicil- } \\
\text { lin in subdural space led to seizures; } \\
\text { immediate diffuse cerebral edema, } \\
\text { stroke; HCP developed by } 6 \text { wks; } \\
\text { withdrawal of care }\end{array}$ \\
\hline Stine \& Harris, 1985 & 32 wks, F & $5 \mathrm{mos}$ & Good & $\begin{array}{l}\text { Stopped infusion, removal of catheter, sub- } \\
\text { dural tap, placement of subdural drain }\end{array}$ & $\begin{array}{l}\text { NEC led to PICC line through scalp vein; } \\
\text { normal neurological exam at } 5 \text { mos } \\
\text { adjusted age }\end{array}$ \\
\hline Young et al., 1989 & 30.5 wks, M & $8 \mathrm{mos}$ & Good & $\begin{array}{l}\text { Stopped infusion, subdural tap, then removal } \\
\text { of catheter, supportive }\end{array}$ & $\begin{array}{l}\text { 8-mo follow-up HC 75th percentile; 4-mo } \\
\text { development at 5-mo adjusted exam }\end{array}$ \\
\hline Rushforth et al., 1991 & 36 wks, F & 17 wks & Death & $\begin{array}{l}\text { Stopped infusion, subdural tap, then removal } \\
\text { of catheter, supportive }\end{array}$ & $\begin{array}{l}\text { Died of respiratory failure; seizure led to } \\
\text { US showing subdural collection }\end{array}$ \\
\hline Tuthill et al., 1998 & 28 wks, F & 103 days & Death & $\begin{array}{l}\text { Stopped infusion, removal of catheter, } \\
\text { subdural tap, supportive }\end{array}$ & $\begin{array}{l}\text { NEC led to PIV for PN; died of broncho- } \\
\text { pulmonary dysplasia, sepsis }\end{array}$ \\
\hline Gazdik et al., 2003 & Term, M & $2 \mathrm{yrs}$ & Good & $\begin{array}{l}\text { Stopped infusion, removal of catheter, sup- } \\
\text { portive }\end{array}$ & $\begin{array}{l}\text { Gastroschisis; PN infusion associated w/ } \\
\text { seizure, unresponsive to AEDs; normal } \\
\text { development at 2-yr follow-up }\end{array}$ \\
\hline Rosales et al., 2004 & 33 wks, F & 86 days & Death & $\begin{array}{l}\text { Stopped infusion, unknown if catheter } \\
\text { removed, subdural tap }\end{array}$ & $\begin{array}{l}\text { 23-wk EGA; death at } 86 \text { days due to } \\
\text { withdrawal of care due to Malassezia } \\
\text { furfurl meningitis \& hydrocephalus }\end{array}$ \\
\hline Present study & 31 wks, F & $1 \mathrm{yr}$ & Good & $\begin{array}{l}\text { Open drainage \& irrigation of bilateral } \\
\text { intracranial subdural spaces \& lumbar } \\
\text { thecal sac }\end{array}$ & $\begin{array}{l}\text { Clinical development appropriate for age, } \\
\text { MRI shows only minimal gliosis }\end{array}$ \\
\hline
\end{tabular}

$\mathrm{AED}=$ antiepileptic drug; $\mathrm{EGA}=$ estimated gestational age; $\mathrm{HC}=$ head circumference; $\mathrm{HCP}=$ hydrocephalus; $\mathrm{NEC}=$ necrotizing enterocolitis; $\mathrm{PICC}=$ peripherally inserted central catheter; PIV = peripheral intravenous line; PNA = pneumonia; US = ultrasound.

of aspiration to maximize effective drainage and irrigation of the intracranial and intraspinal spaces.

\section{Conclusions}

In the rare event of an inadvertent symptomatic subdural infusion of $\mathrm{PN}$, we propose that drainage of the offending agent should be considered. Open drainage and irrigation of the intracranial and spinal compartments resulted in a good outcome in this child.

\section{Acknowledgment}

We greatly appreciate Devon Truong, PA-C, for illustrative contribution and data collection to the present manuscript.

\section{References}

1. Beaumont E, Malin S, Meny R: Accidental intracranial hyperalimentation infusion. JPEN J Parenter Enteral Nutr 6:532-533, 1982

2. Black VD, Little GA, Marin-Padilla M: Failure of inflammatory response to accidental intracranial lipid infusion. Pediatrics 62:839-842, 1978

3. Cardella JF, Fox PS, Lawler JB: Interventional radiologic placement of peripherally inserted central catheters. J Vasc Interv Radiol 4:653-660, 1993

4. Denny DF Jr: Placement and management of long-term central venous access catheters and ports. AJR Am J Roentgenol 161:385-393, 1993

5. Donaldson JS, Morello FP, Junewick JJ, O’Donovan JC, LimDunham J: Peripherally inserted central venous catheters: US-guided vascular access in pediatric patients. Radiology 197:542-544, 1995

6. Gazdik M, Robrevezmanic V, Saina G, Zubovic I, Ahel V, Dessardo S: Neonatal status epilepticus caused by subarachnoidal content of total parenteral nutrition regimen. Pediatr Int 45:345-346, 2003

7. Leick-Rude MK, Haney B: Midline catheter use in the intensive care nursery. Neonatal Netw 25:189-199, 2006

8. Means SW, Spampinato MV, Rao AG, Hill JG: Preterm infant with subdural hematoma from malpositioned scalp intravenous catheter. Adv Neonatal Care 11:251-254, 2011

9. Pearce JM: The craniospinal venous system. Eur Neurol 56:136-138, 2006

10. Rosales CM, Jackson MA, Zwick D: Malassezia furfur meningitis associated with total parenteral nutrition subdural effusion. Pediatr Dev Pathol 7:86-90, 2004

11. Rushforth A, Green MA, Levene MI, Puntis JW: Subdural fat effusion complicating parenteral nutrition. Arch Dis Child 66:1350-1351, 1991

12. Stine MJ, Harris H: Subdural collection of intravenous fat emulsion in a neonate. Complication of central venous catheterization for total parenteral nutrition. Clin Pediatr (Phila) 24:40-41, 1985

13. Stringer MD: Subdural fat effusion complicating parenteral nutrition. Arch Dis Child 67:567-568, 1992

14. Tuthill DP, Samuel L, Morris S, Drayton M: Neonatal sub- 
dural transudation of total parenteral nutrition. J Pediatr Gastroenterol Nutr 27:359-361, 1998

15. Wolfe BM, Ryder MA, Nishikawa RA, Halsted CH, Schmidt BF: Complications of parenteral nutrition. Am J Surg 152:93-99, 1986

16. Young S, MacMahon P, Kovar IZ: Subdural intravenous fat collection: an unusual complication of central intravenous feeding in the neonate. JPEN J Parenter Enteral Nutr 13:661-662, 1989

\section{Author Contributions}

Conception and design: Tuite, Ahmadian. Acquisition of data: Tuite, Ahmadian, Manwaring, Truong. Analysis and interpretation of data: Truong. Drafting the article: Tuite, Ahmadian, Manwaring. Critically revising the article: Tuite, Ahmadian, Manwaring, McCarthy, Rodriguez, Carey. Reviewed submitted version of manuscript: Tuite, Ahmadian, McCarthy, Rodriguez, Carey. Administrative/technical/material support: Truong, Rodriguez, Carey. Study supervision: Tuite, Rodriguez, Carey. Illustration: Truong.

\section{Supplemental Information}

Videos

Video 1, Media Player. http://mfile.akamai.com/21490/wmv/ digitalwbc.download .akamai.com/21492/wm.digitalsource-naregional/peds13-34_video_1.asx.

Video 1, Quicktime. http://mfile.akamai.com/21488/mov/ digitalwbc.download.akamai.com/21492/qt.digitalsource-global/ peds13-34_video_1.mov.

\section{Correspondence}

Gerald Tuite, Neuroscience Institute, All Children's Hospital/ Johns Hopkins Medicine, 601 5th St. S, Ste. 511, Saint Petersburg, FL 33701. email: geraldtuite@gmail.com. 